ARTIGOS

\title{
DIÁRIO FORMATIVO: OS ESTUDANTES DE CIÊNCIAS SOCIAIS E SEU PROCESSO DE FORMAÇÃO
}

\author{
Erivania Melo de Morais \\ Universidade Estadual do Rio Grande do Norte - UERN \\ Assu, Rio Grande do Norte - Brasil \\ moraiserivania@gmail.com \\ https://orcid.org/0000-0003-1839-6069 \\ Irene Alves de Paiva \\ Universidade Federal do Rio Grande do Norte - UFRN \\ Natal, Rio Grande do Norte - Brasil \\ irenealvesp@gmail.com \\ https://orcid.org/0000-0002-2955-4328
}

RESUMO: Este artigo apresenta resultados preliminares da nossa pesquisa de doutoramento e objetiva refletir sobre a formação docente a partir da alternativa metodológica "Diário formativo", que foi desenvolvida com estudantes da licenciatura em ciências sociais da Universidade Federal do Rio Grande do Norte - UFRN, durante um curso de extensão, denominado de "Formação e profissão de professores em ciências sociais: perspectivas teóricas-metodológicas e os desafios da prática" realizado em 2019. Assim, elencamos como objetivos específicos: Problematizar o diário formativo como uma alternativa metodológica possível para o processo de formação e autoformação; Contextualizar os sujeitos da pesquisa; Apontar reflexões iniciais acerca da escrita dos diários formativos. Assim, optamos por uma metodologia de caráter qualitativo, com revisão teórica pautado em Ardoino (1998); Barbosa (1998; 2000; 2008); Barbosa e Hess (2010); Hess e Weigand (2006), entre outros e análise parcial dos diários formativos dos estudantes participantes da pesquisa. Para as análises, nos apoiamos na abordagem multirreferencial e em Bardin (2010) com análise de conteúdo, no qual, foi possível evidenciar: a relevância de construir alternativas de escrita de si; o fomento de uma formação autônoma, crítica e reflexiva; e autoformação que permita o sujeito se perceber no processo formativo e transformar suas ações na sua relação com cotidiano.

PALAVRAS-CHAVE: Diário Formativo; Formação docente; Autoformação. 


\title{
FORMATIVE DIARY: SOCIAL SCIENCE STUDENTS AND THEIR TRAINING PROCESS
}

\begin{abstract}
This article presents preliminary results of our doctoral research and aims to reflect on teacher education from the alternative methodological "Diário Formativo" (training diary), which was developed with undergraduate students in social sciences at the Universidade Federal do Rio Grande do Norte - UFRN, during their extension course, called "Teacher training and profession in social sciences: theoretical-methodological perspectives and the challenges of practice ", realized in 2019. Thus, we list as specific objectives: to problematize the diary training as a possible methodological alternative to the process of training and self-training; contextualize the research subjects; signalize early reflections about writing the training diaries. Thus, we opted for a qualitative methodology, with theoretical review based on Ardoino (1998); Barbosa (1998; 2000; 2008); Barbosa and Hess (2010); Hess and Weigand (2006), among others, and partial analysis of training diary of students participating in the research. For analysis, we based in the approach multireferential from Bardin (2010) with content analysis, in which it was possible to point: the relevance of building self-writing alternatives; the promotion of a autonomous, critical and reflective training; and self-training that allows to the subject to perceive himself in the formative process and transform his actions in his relationship with daily life.
\end{abstract}

KEYWORDS: Training Diary; Teacher Formation; Reflective Training. Self-training.

\section{JOURNAL DE FORMATION: LES ÉTUDIANTS EN SCIENCES SOCIALES ET LEURS PROCESSUS DE FORMATION}

RÉSUMÉ: Cet article présente les résultats préliminaires de notre recherche doctorale et vise à réfléchir sur la formation des enseignants à partir de l'alternative méthodologique "Diário Formativo" (Journal de formation), qui a été développé avec des étudiants du premier cycle en sciences sociales à l'Universidade Federal do Rio Grande do Norte - UFRN, pendant leurs cours d'extension intitulé «Formation et profession des enseignants sciences sociales: perspectives théorico-méthodologiques et enjeux de la pratique " réalisée en 2019. Ainsi, nous listons comme objectifs spécifiques: problématiser le journal de formation comme alternative méthodologique possible au processus de formation et d'auto entrainement; contextualiser les sujets de recherche; soulignez les réflexions premières sur la rédaction des journaux de formation. Ainsi, nous avons opté pour une méthodologie qualitative, avec la revue théorique basé sur Ardoino (1998); Barbosa (1998; 2000; 2008); Barbosa et Hess (2010); Hess et Weigand (2006), entre autres, et l'analyse partielle des journaux de formation des étudiants participants à la recherche. Pour l'analyse, nous nous appuyons dans l'approche multiréférentiel et à Bardin (2010) avec l'analyse de contenu, dans laquelle il était possible mettre en évidence: la pertinence de construire des alternatives d'auto-écriture; la promotion d'une formation autonome, critique et réflexive; et l'auto-formation qui permet au sujet se percevoir dans le processus formatif et transformer ses actions en son rapport avec la vie quotidienne.

MOTS-CLÉS: Journal de Formation; Formation des Enseignants; Auto-formation. 


\section{NOTAS INICIAIS}

A formação docente tem sido objeto de muitos estudos e pesquisas, assim como, os recursos metodológicos utilizados para refletir, problematizar, analisar e fomentar os processos formativos. Recentemente tivemos avanços em muitos desses recursos que se pautam em novas tecnologias, em sistemas operacionais ultra modernos, ou seja, o mundo marcado pela indústria 4.0, tem ganho espaços cada vez mais significativos nas investigações, nas interpretações, no tratamento de dados e até mesmo na relações interpessoais e sociais.

Desse modo, na tentativa de desenvolver perspectivas metodológicas que perpassam o universo subjetivo, mas sem deixar de apreender a dimensão da totalidade da realidade social do sujeito, resgatamos o diário como uma alternativa formativa de interpretar e conhecer o ponto de vista do outro sobre seus processo de formação.

Barbosa e Hess (2010) ao pensarem o "diário de pesquisa", buscaram "redescobrir" o sentido da escrita como uma alternativa pertinente de elaboração de si, superando a dimensão mecânica a que tem sido reduzida a vida social, assim como, rompendo com as concepções e sentidos formulados sem que haja interpretação, compreensão, questionamentos desses significados.

Assim, a partir dessa inquietação, nos questionamos: seria possível o diário ser entendido como uma alternativa metodológica formativa de conhecimento do sujeito e da realidade social no qual está inserido?

Para tentar problematizar esta questão, buscamos refletir sobre a formação docente a partir da alternativa metodológica "Diário formativo", que foi desenvolvida com estudantes da licenciatura em Ciências Sociais da Universidade Federal do Rio Grande do Norte - UFRN, durante um curso de extensão, denominado de "Formação e profissão de professores1 em ciências sociais: perspectivas teóricas-metodológicas e os desafios da prática", realizado nos meses de novembro e dezembro de 2019.

Nesse sentido, elencamos como objetivos específicos: Problematizar o diário formativo como uma alternativa metodológica possível para o processo de formação e autoformação, conhecendo as persepctivas teóricas que o embasa; contextualizar os sujeitos da pesquisa e; apontar reflexões preliminares acerca da escrita dos diários formativos escritos pelos estudantes.

Assim, para compreender o que estamos denominando de Diário formativo enquanto uma alternativa metodológica para a formação e autoformação de estudantes, é importante nos aproximarmos do diário de pesquisa (BARBOSA E HESS, 2010), que foi base para o nosso processo de autoria e ressignificação do recurso, assim como, os fundamentos da multirreferencialidade, como aporte epistemológico reflexivo para pensarmos uma formação autônoma, emancipadora, crítica, implicada e criadora.

O Diário formativo aqui desenvolvido, perpassa por duas perspectivas: primeiro por apreender o sentido do diário nas concepções de Barbosa e Hess (2010), que são diaristas e utilizam essa alternativa para desenvolver reflexões que os auxiliaram nos processos formativos de estudantes nas Universidades em que atuam,

1 A escolha por "Profissão de professores" se deu no início do doutoramento, no primeiro semestre de 2019.1 - entre os meses de março e maio -, em que estávamos passando pelo comitê de ética e precisavámos enviar todos os recusos metodógicos antecipadamente, mesmo se esses não tivessem amadurecidos, como foi o nosso caso. Ao iniciar as nossas imersões no campo de pesquisa e com aprofundamento nas leituras, passamos a entender e a refletir acerca da importância do uso das linguagens, e durante todas as aplicações, os sentidos explicativos dos recursos, estavam dentro da compreensão da docência num sentido mais amplo, ou seja, da profissão docente, o que nos parece ser algo relevante de se salientar, tendo em vista que, as linguagens são marcadores históricos, de opressões e de reparação histórico-social e que portanto, necessitam ser revisitados e colocados em prática. 
fazendo parte de suas trajetórias enquanto docentes/pesquisadores; e a segunda perspectiva e o dialogo com a multirreferencialidade, que nos permite ampliar as nossas referências e conhecimentos acerca da formação docente, no que diz respeito, às dimensões da subjetividade e da realidade objetiva que atravessam os processos formativos, e que nos permitiu um olhar plural sobre o objeto de pesquisa, assim como, dos processos metodológicos, sem espaços para reduções epistêmicas ou negação teórica, mas construção e ressignificação de conhecimentos a partir de saberes diversos que dialogam.

Para desenvolver a reflexão acerca dos objetivos, optamos por uma metodologia de caráter qualitativo, uma vez que, Minayo (2002) aponta que a pesquisa qualitativa responde a questões particulares e que nas ciências sociais reflete acerca do universo de significados e não apenas persepctivas quatificavéis, assim, utilizaremos como recusos metodológicos a revisão bibliográfica pautado em Ardoino (1998); Borba (1998); Barbosa (1998; 2000; 2008); Hess (2009); Barbosa e Hess (2010); Hess e Weigand (2006); Lahire (2005); Berger e Luckmann (2012); Morais (2019), entre outros autores e no recurso "diário formativo" dos estudantes participantes da pesquisa de doutoramento, na qual realizamos uma análise parcial, tendo como respaldo Bardin (2010) com análise de conteúdo, assim como, na perspectiva multirreferencial.

Para melhor sistematização, dividimos o texto em três momentos. O primeiro denominado de " O Diário formativo: uma alternativa metodológica de formação e autoformação de estudantes", no qual problematizamos teoricamente de onde nos embasamos para pensar este recurso. Em segundo, dialogamos com "Os estudantes de ciências sociais e o processo de formação docente", em que apresentamos os participantes da pesquisa e no terceiro momento, abordamos "Análises preliminares da escrita de si: construindo o Diário formativo", que interpretamos três perspectivas acerca da formação que foram abordados pelos estudantes durante a participação no curso de extensão. Por fim, sucitamos algumas breves considerações acerca do diário formativo como uma alternativa metodológica de escrita de si, como um processo de formação autonoma, crítica e reflexiva e como um recusos que possibilita o reconhecimento de si como sujeito histórico.

\section{O Diário Formativo: uma alternativa metodológica de formação e autoformação de estudantes.}

O diário formativo como uma alternativa metodológica, surgiu a partir dos nossos estudos e aprofundamentos a respeito da abordagem multirreferencial no Programa de Pós-Graduação em Ciências Sociais, quando assumimos essa abordagem como o apoio epistemológico da nossa pesquisa de doutoramento.

Dentro do processo de bricolagem da pesquisa, passamos a nos aproximar de teorias e perspectivas metodológicas que dialogassem com o nosso objeto, e que para além dessa aproximação, passassem a criar ou ressignificar recursos que pudessem desvelar o nosso objeto de pesquisa, porque "É o fazer ciência, o criar, o construir ciência que definirá a "composição" (a bricolagem) metodológica. [...] e não o inverso". (BORBA, 1998, p. 17)

O diário foi pensando dentro de um processo de investigação, de aprofundamento teórico, e sobretudo, de momentos coletivos de diálogos e reflexões a partir do contato com o grupo de pesquisa do professor Joaquim Barbosa, que nos possibilitou pensar e ressignificar os recursos a partir do nosso objeto e objetivos, de modo a não apenas reproduzir, mas de reconfigurar criativamente outras formas de realizar a coleta dos dados. 
Assim, surgiu o primeiro movimento de ressignificação metodológica, a partir das leituras dos grupos focais e grupos reflexivos, que foi o "Encontro Reflexivo Dialogal - ERD" ${ }^{2}$ como uma alternativa formativa que permitissem que os estudantes participassem do processo de construção do conhecimento de forma autônoma, uma vez que,

Os Encontros Reflexivos Dialogais - ERD - precisam ser entendidos antes de qualquer coisa como um processo de autorização, que é flexível, e que pode se ajustar a pesquisas que busquem para além de uma discussão com base em temática ou questão, suscitar um processo formativo em que os participantes sejam parte e se sintam parte do momento dialogado. (MORAIS, 2019, p. 201)

O ERD, buscou em seu processo de ressignificação, avançar as formas fixas de temáticas, questões problemas, situações previamente elaborados para a formação dos debates e criou eixos de discussões de forma coletiva a partir do que os estudantes demandassem.

E nesse processo, deveriam registrar seus pontos de vista sobre a vivência nesse momento de formação. É desse modo, que o diário formativo surge, como um recurso complementar ao Encontro Reflexivo Dialogal - ERD, e passa a ter seu protagonismo na pesquisa, permitindo os estudantes o registro íntimo, mas social das suas experiências, de suas reflexões, pensamentos a partir do processo de formação.

O diário formativo, no qual utilizamos na pesquisa e estamos constituindo uma reflexão, parte do recurso "diário de pesquisa" problematizado por Barbosa e Hess, (2010), e nesse sentido, se coloca como um ponto relevante, apresentarmos o que é o Diário de pesquisa ou Jornal de Pesquisa, tendo em vista que a, " palavra francesa Journal pode ser traduzida em português como "diário" ou como "jornal". (BARBOSA, 2010, p. 19), que carrega em seu significado tanto o sentido do diário como uma escrita íntima, mas que pode se tornar pública, havendo a possibilidade de se construir um movimento de socialização da escrita e publicizá-la de algum modo.

Nesse sentido, o diário de pesquisa foi pensando como um recurso processual para auxiliar o estudante universitário em sua autoformação, e que compreendia três elementos que perpassariam esse processo, sendo respectivamente: a formação para a pesquisa, para a escrita e para si "como autor de sua atuação no social da vida cotidiana" (BARBOSA; HESS, 2010, p. 15).

E esse cotidiano expressa também uma tríade relação na formação dos sentidos e significados desse mundo vivido e como esses implicam as nossas ações e as nossas concepções de mundo, que são amalgamados pela inter-relação entre realidade objetiva, historicidade e a subjetividade, que configuram o elo que nos fazem refletir acerca dos componentes do vivido, das relações sociais que constituímos.

Assim, a realidade da vida cotidiana está organizada em torno do aqui e do agora, ou seja, do presente e este "aqui e agora" é o foco da atenção para com à realidade da vida cotidiana" (BERGER; LUCKMANN, 2012, p. 38), por isso, que o diário tem essa dimensão de uma escrita de si, mas relacionada ao social e ao cotidiano, porque é também uma escrita do presente.

Embora o diário não seja uma atividade recente é ao mesmo tempo atual, porque permite dois movimentos dialeticamente imbricados, que é essa escrita de si no presente e a possibilidade de se ver passar pelo

2 Os Encontros Reflexivos Dialogais é um recurso metodológico que teve como base os estudos dos grupos focais e grupos reflexivos que buscou superar as formas fixas de debates e eixos constituidos previamente, mas permitindo a formação coletiva dessas reflexões dialogadas. Ver MORAIS (2019) 
processo, ou seja, de identificar as mudanças, os avanços e os aprendizados no decorrer de uma trajetória e de suas experiências cotidianas.

Hess e Weigand (2006), afirmam que a primeira sistematização de diário foi de autoria de Marc-Antoine Jullien em 1808, propondo aos jovens a escrita de três diários: o do corpo, relacionado a saúde, o diário da alma, que trata do encontrar-se com o outro e com o que se adquire deles, e por fim o intelectual, que se anota os conhecimentos adquiridos em encontros com leituras ou pessoas.

O diário de pesquisa propõe uma escrita com significado, ou seja, a busca de sentido para aquilo que se aprende, de se autorizar enquanto sujeito que pensa e que compreende o seu lugar no mundo e com o mundo, e desenvolver no estudante, futuro pesquisador, uma postura reflexiva, interrogativa, curiosa sobre a vida que o rodeia e acerca de si mesmo, por isso que a proposição de diário de pesquisa implica,

uma proposição de visão plural para a realidade que se quer compreender, ou seja, a passagem de uma escrita pessoal para uma escrita pública: a possibilidade da escrita pessoal, despreocupada, criadora, como registro livre, ao mesmo tempo significativo para o sujeito que escreve, mas que traz em seu bojo a possibilidade e o desejo contido de se tornar pública. (BARBOSA; HESS, 2010, p.34)

Essa proposição de escrita implicada que é o diário ou Jornal de Pesquisa, apesar de ter em sua essência a dimensão pessoal, íntima, abarca constituição sistemática e organização do caminho percorrido, da escrita reflexiva, da escrita ética e política que apresenta-se pessoal, mas com relação na coletividade e portanto, busca tornar-se pública.

Barbosa (2000) desvela que o diário de pesquisa vai para além de uma escrita simples e pessoal, e torna-se uma escrita pública e social, porque ela incentiva a escrita cuidadosa, reflexiva, promove a organização de anotações que podem se transformar em dados para uma pesquisa.

O diário pode ser um recurso relevante para quem quer compreender a sua prática, pensando-a, organizando-a e transformando-a a medida em que suas ideias emergem e passam a atuar congruentemente, ou seja, o diário se coloca para os autores como uma forma de escrita implicada é portanto um forma de "trabalhar a congruência" (HESS; WEIGAND, 2006, p. 16)

Essa escrita implicada que é proposta pelo diário, sugere captar no dia a dia, as perspectivas, as experiências, as vivências, os sentimentos, os diálogos, mas também as angústias das relações subjetivas e intersubjetivas com o cotidiano e com a realidade social, além de permitir ao sujeito que escreve sobre o seu processo, a elaboração de sentidos e significados desse caminho percorrido e das relações que são constituídas socialmente.

De acordo com Hess e Weigand (2006) o diário é uma forma de escrita calorosa, no qual o autor capta o que se passa, o que observa, percebe e concebe num dado momento, é um registro daquilo que faz sentido ou aquilo que o movimenta.

Assim, o objetivo do diário seria guardar as memórias, para si mesmo e para os outros, mas para além disso, o diário efetiva uma possibilidade de transformação de si no processo de caminhada. Ou seja, quando registramos momentos, sentimentos, reflexões, pensamentos, desejos, medos, angústias, não estamos apenas registrando uma memória, mas guardando uma parte de nós, que se mantém ou que se transformou com as relações e os processos de socialização ocorridos ao longo de nossas trajetórias. 
Lahire (2005) ao pensar os processos de socialização, vai compreendê-los como um sistema útil que não pode ser entendido, analisado e interpretado sob um único viés, mas a partir de outras perspectivas que façam parte do mundo social e esses sujeitos sociais, constituem patrimónios individuais de conhecimento, de concepção, de pensamentos, acumulados ao longo de suas experiências e vivências.

Daí a relevância de se registrar esses momentos que podem ser perdidos na memória, porque como ressalta Michel Pollak (1992) a memória tem elementos individuais e coletivos, primeiro pelo fato da memória guardar acontecimentos vividos pessoalmente e segundo, esses acontecimentos são quase sempre vividos coletivamente, que seria o que o autor denomina de "vividos por tabela", por ser acontecimentos que nem sempre os sujeitos participam, mas que se tornam fortes no imaginário.

Nesse sentido, a escrita de si se torna relevante, porque permite registrar o acontecimento vivido no presente e ser acionado no futuro, não ficando apenas no imaginário, mas torna-se fonte, dado, para ser analisado, refletido, retornado, ressignificado.

Existem diversas formas de diário, segundo Hess e Weigand ( 2006 ), que podem ser uma alternativa para a formação e autoformação, dentre os quais os autores evidenciam o diário íntimo; de viagem; filosófico; de pesquisa; de formação; institucional; dos momentos, como demonstrado no esquema abaixo.

Esquema 1 - Formas de Diário

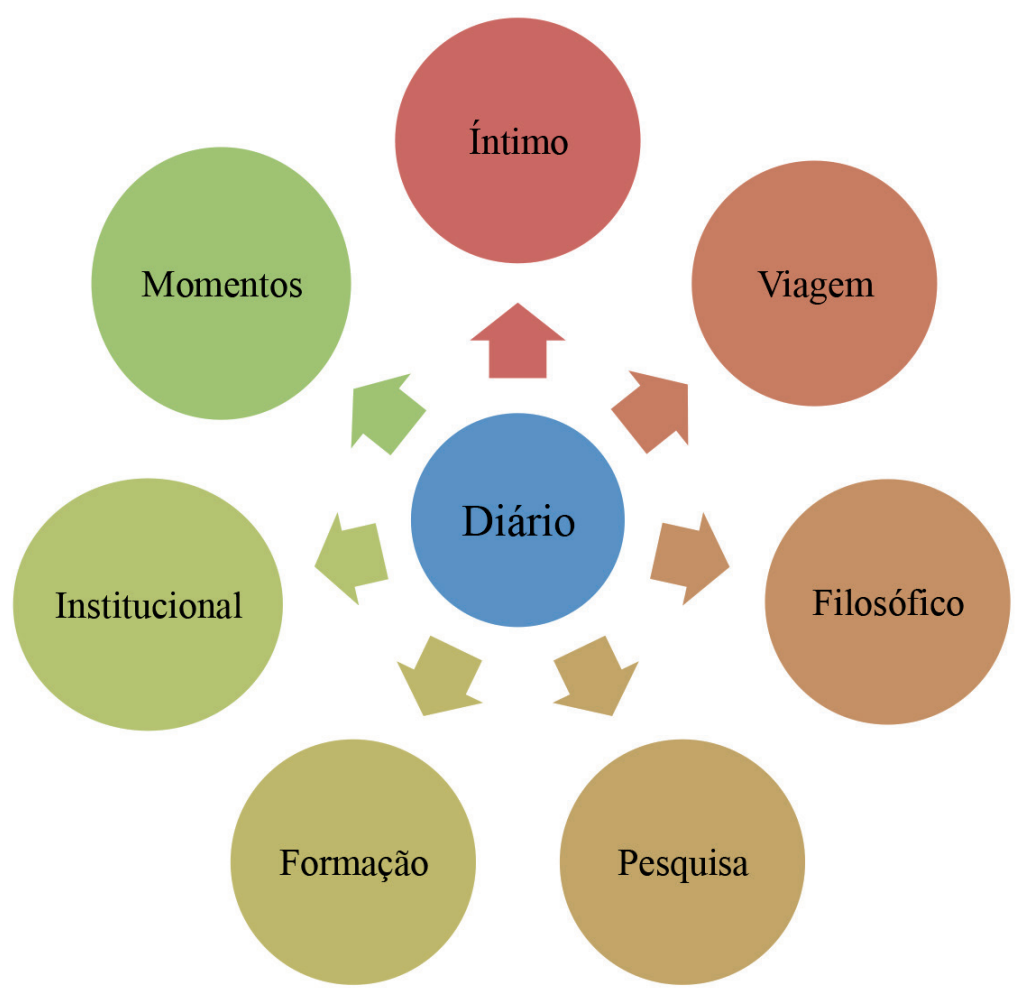

Fonte: (HESS; WEIGAND, 2006). Elaborado pelas autoras. 
De acordo com Hess e Weigand (2006), o diário íntimo ou pessoal é aquele construído por pessoas, seja, jovem, adulto, adolescente, etc, e que tem como finalidade o registro da vivência pessoal.

Já o diário de viagem, segundo Hess e Weigand (2006), não objetiva dar conta da vida toda dos sujeitos, mas se limita a um período específico de uma ou várias viagens. É uma forma particular deste diário é o de bordo, muito utilizado nas grandes expedições que partiram para encontrar outros territórios. O diário filosófico, realiza mediações e reflexões com o dia a dia, registrando as nossas ideias e pensamentos.

O diário de pesquisa, pode ser o momento em que o pesquisador, registra seus objetivos, suas hipóteses, sua metodologia, ou ainda o registro reflexivo de autores nos quais tem se aprofundado. (HESS EWEIGAND, 2006)

Em relação ao diário de formação, Hess e Weigand (2006), apontam como um possível registro da vivência cotidiana em sua prática, ou em processos formativos, este diário é o que mais se aproxima do nosso diário formativo desenvolvido durante a nossa imersão no campo da pesquisa doutoral.

Hess e Weigand (2006) ainda salientam o diário institucional, que busca dar conta das dimensões individuais, interindividuais, grupais, da vida em um determinado instituição. E por fim, apresentam o diário dos momentos, evidenciando as experiências e o cotidiano a partir de diversas perspectivas a partir de situações contextualizadas da vida.

O diário é uma escrita, e um tipo de narrativa que pode ser construído com uso de diversas alternativas, pode ser realizado com uma escrita em caderno ou mesmo de forma gravada, visto que, o que faz parte de sua essência é o registro de uma vivência ou experiência subjetiva, sentida e significada pelo sujeito socialmente.

O diário precisa ser construído no dia a dia, permitindo uma congruência entre o momento da escrita e o momento da leitura. Pode ser escrito a noite ou no dia seguinte, e contrariamente ao que se tem em histórias de vidas e memoriais, a escrita pessoal através do diário é restrita a apreensão das vivências do presente, ou seja, abarca a realidade vivida pelo sujeito, assim, o que se escreve é o momento vivido, o que está sendo refletido, pensando no momento presente.

Não é uma escrita impactada por reflexões de acontecimentos passados, mas está sob o efeito do impacto do acontecimento no presente. Há na escrita do diário uma espontaneidade, uma força de sentimentos e a falta de distanciamento e parcialidade, mas que pode nos dar uma compreensão da relação subjetiva com a realidade social vivida.

O autor - quem escreve o diário -, é uma pessoa ou pode ser um coletivo, numa sala de aula, quando se quer registrar o processo ensino-aprendizagem dos estudantes através de um projeto de pesquisa, é possível que toda a turma se mobilize e tenha seu dia de escrever como foi aquele momento, aquela aula, o que foi tratado nos textos, nas reflexões, mas, o autor do diário comumente, se trata de uma escrita individual que pode tornar-se social com resultados de pesquisas ou textos públicos. (HESS E WEIGAND, 2006)

O diário na concepção de Hess e Weigand (2006) é uma forma de exploração transversal, visto que, mesmo focando em um objeto, objetivo, não se limita a ele, pode atravessar várias ideias e outras perspectivas de perceber as experiências e vivências.

Por isso que, a escrita do diário é plural, não é constituída a partir de uma única realidade fixa, mas das transformações cotidianas e das trajetórias e eventos nas quais vivenciamos, por isso, que dialoga com a 
abordagem multirreferencial que propõe "...uma leitura plural de seus objetos (práticos ou teóricos), sob diferentes pontos de vista, que implicam tanto visões específicas quanto linguagens apropriadas às descrições exigidas..." (ARDOINO, 1998, p.24)

Posteriormente, vamos contextualizar os sujeitos da pesquisa na relação com a formação realizada através do curso de extensão entre os meses de novembro à dezembro de 2019.

\section{Os estudantes de ciências sociais e o processo de formação docente.}

A formação docente em ciências sociais, tem passado por muitos momentos de aprofundamento e de rompimento com modelos formativos rígidos e sobretudo, de reprodução de um viés bacharelesco.

Nos últimos anos com as mudanças nas políticas educacionais de formação docente, tem se buscado diálogos constantes com as ciências da educação para se pensar novos currículos, práticas, metodologias que permitam os estudantes das licenciaturas compreender a função social da docência, assim como, as realidades diversas no espaço escolar.

Pensando nisso, elaboramos um curso de extensão intitulado de "Formação e profissão de professores em ciências sociais: perspectivas teóricas-metodológicas e os desafios da prática", que teve como objetivo fomentar o debate sobre a formação e prática docente dos estudantes que tiveram ou estavam tendo contato com a docência em escolas estaduais do município de Natal, no Rio Grande do Norte, através da residência pedagógica, dos estágios supervisionados de formação docente ou via Programa Institucional de Bolsas de Iniciação à docência - PIBID.

Os participantes que se inscreveram no curso, o fizeram por livre espontânea vontade, mas foram parte de um grupo maior, durante a nossa coleta de dados, através dos recursos metodológicos da pesquisa de doutoramento, onde aplicamos inicialmente questionários socioeconômicos e culturais e a Técnica de Associação Livre $(T A L)^{3}$ com os estudantes da licenciatura em ciências sociais que estavam nos últimos periodos do curso tendo uma totalidade de 22 estudantes e desses, 7 decidiu participar do curso de formação.

Gráfico 1 - Total de participantes do curso de extensão.

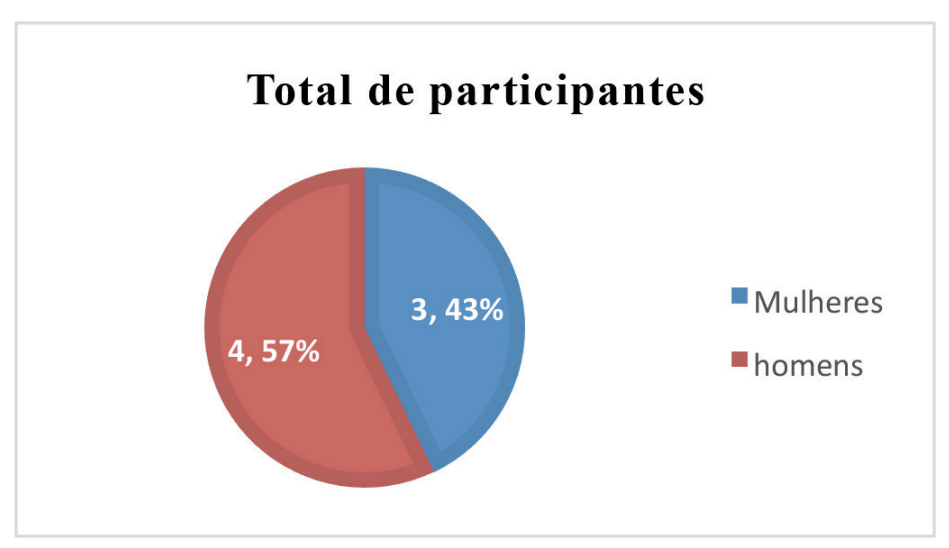

Fonte: Elaborado pelas autoras.

\footnotetext{
3 O recurso metodológico "Técnica de Associação Livre" é uma ressignificação da Técnica de Associação Livre de Palavras - TALP a partir dos estudos de Melo (2005), que consiste em um espaço para o preenchimento das palavras relacionadas ao termo indutor e que é hieraquizada, entretanto, no nosso modelo, ao invés de palavras, são registradas expressões (palavras e ou frases) relacionadas ao termo indutor e não há hierquização, tendo em vista que os sentidos atribuídos são analisados em sua complexidade e não em níveis de importância.
} 
Dos sete estudantes que tiveram interesse em participar da pesquisa, como demonstra o gráfico 1, três eram mulheres representando $43 \%$, e quatro eram homens, caracterizando $57 \%$ dos total de participantes, um grupo bem heterogêneo e interativo, que durante os encontros demonstraram interesse pelas temáticas debatidas no decorrer da formação.

Esses estudantes que participaram do curso de formação são de classes populares, moram nas periferias e nas regiões metropolitanas de Natal/RN. Dos setes estudante, seis eram bolsistas da residência pedagógica ou do PIBID, e um trabalhada na docência dando aulas em cursinho popular, mas mesmo com as bolsas alguns do estudantes tinham algum tipo de atividade autônoma, para complementar as rendas de suas casas.

Já no gráfico 2, é possível observar que os estudantes tinham idades entre 25 anos a 34 anos, demonstrando um grupo experiente, que nos Encontros Reflexivos Dialogais, passaram a construir coletivamente as temáticas que seriam debatidas posteriormente, sendo esta, uma das principais características desses "Encontros", constituir um processo formativo coletivo e que teve como ponto de partida o interesse do estudante em formação.

\section{Gráfico 2 - Idade dos participantes.}

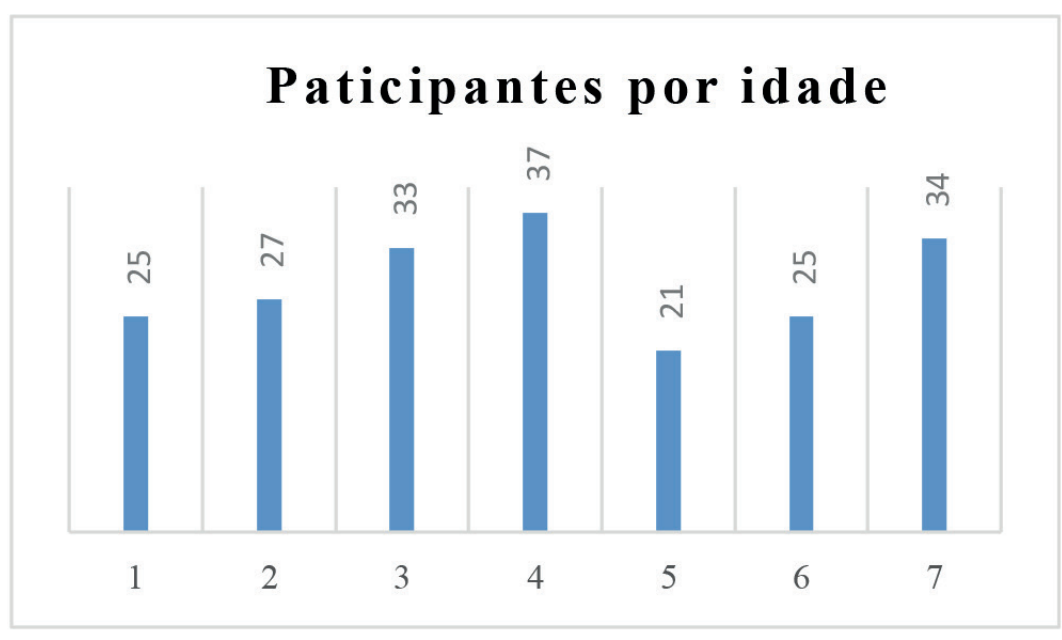

Fonte: Elaborado pelas autoras.

Ainda pensando nesses processos coletivos, apesar de termos elaborado o projeto de extensão, com objetivos, metodologias, justificativa, não fixamos temáticas para serem discutidas previamente durante os seis encontros, a dinâmica partiu de uma reflexão coletiva que demandou a curiosidade e o interesse dos estudantes.

Assim, no primeiro encontro, denominado de "Acolhimento reflexivo", apresentamos a proposta e a partir de uma conversa sobre a prática docente, sobre a atuação docente e sobre a realidade, a partir de das perspectivas de Paulo Freire (2019) com seu livro "Pedagogia da autonomia", que após o debate os estudantes participantes deixaram registrados, as suas inquietações, sobre o que gostariam de dialogar no próximo encontro em envelopes.

E essa dinâmica foi realizada durante todos os demais momentos, sempre no final de cada reflexão, de cada debate e diálogos, os estudantes, anotavam as suas inquietações, sugestões e perguntas para serem pensadas, problematizadas e refletidas nos Encontro Reflexivo Dialogal. 
E foi ainda nesse primeiro encontro, que os estudantes receberam um material, no qual constava, uma pasta, um texto do professor Joaquim Barbosa, denominado de "Educação para a formação de autores - cidadãos" e o "Diário Formativo", para que pudessem registrar, a partir da experiência de cada um, os encontros, os debates, as reflexões, ou as angústias, as críticas e todas as ideias e pensamentos que acionassem a vivência do curso de formação com o grupo ou em outros espaços.

Esse momento foi seguido ainda de uma mediação em que explicitamos o que era o diário e o porquê que estávamos o utilizando, e durante o processo foi possível observar que cada um criou a sua forma de registrar, não havendo uma homogeneização na construção metodológica da escrita, ou seja, cada estudante participante do curso tornou-se autor de si.

Em seguida vamos suscitar brevemente alguns pontos que foram escrito pelos estudantes ao longo das seis semanas de curso.

\section{Análises preliminares da escrita de si: construindo o diário formativo}

Partindo da compreensão de que cada sujeito é único no processo, e que haveria certa rejeição em relação a essa escrita implicada do caminho formativo, nem todos os estudantes devolveram o diário para que pudéssemos realizar a reflexão a respeito da formação docente, do curso e da escrita de cada um, dos pontos de vistas, dos pensamentos, das críticas registradas desses momentos, visto que, é uma proposta de registro complexo da escrita de quem o faz, "...pois não nasce de uma ideia pronta, mas em mobilizar um processo em construção que se dá em diferentes níveis e estratégias de trabalho..." (FORMIGA; BARBOSA, 2006, p. 54)

Os estudantes a partir desse contato com a escrita implicada, se autorizaram e passaram a registrar o diário cada um na sua particularidade, ou seja, tiveram aqueles, que registraram pontos que foram abordados em cada encontro, colocando os temas que foram construídos, outros, evidenciaram a data e escreveram em forma de texto na primeira pessoa, alguns escreveram mais, outros tiveram uma escrita mais resumida, mas, foi possível apreender algumas perspectivas relevantes sobre a formação, sobre o que aquele momento significou, sobre a vivência deles na docência, entre outros pontos que serão posteriormente refletidos. Dos sete participantes, apenas cinco devolveram o diário formativo e os outros dois argumentaram que não conseguiram realizar essa escrita.

Neste trabalho, trouxemos três reflexões realizadas por cada participante sobre o processo formativo a partir da vivência com o curso e com o grupo, sinalizado no quadro abaixo. 
Quadro 1 - Pontos levantados pelos estudantes no diário.

\begin{tabular}{|c|c|c|c|c|}
\hline Participante 1 & Participante 2 & Participante 3 & Participante 4 & Participante 5 \\
\hline $\begin{array}{l}\text { Ressaltou as } \\
\text { mudanças na } \\
\text { grade curricular } \\
\text { do curso; } \\
\text { Que cada esco- } \\
\text { la é diferente e } \\
\text { que por isso a } \\
\text { teoria sociologi- } \\
\text { ca é relevante; } \\
\text { A importância } \\
\text { de pensar a } \\
\text { escola e a sala } \\
\text { de aula; }\end{array}$ & $\begin{array}{l}\text { Evidenciou o início } \\
\text { do Encontro, } \\
\text { sobre as reflexões } \\
\text { freireanas; } \\
\text { Apontou que } \\
\text { lembrar das obras } \\
\text { de Paulo Freire fez } \\
\text { com que pensasse } \\
\text { no que os alunos } \\
\text { disseram, como } \\
\text { por exemplo a } \\
\text { escola ser uma } \\
\text { obrigação, que } \\
\text { não tinham como } \\
\text { estudar em casa } \\
\text { tranquilamente. } \\
\text { Abordou a } \\
\text { importância } \\
\text { de uma prática } \\
\text { docente } \\
\text { contextualizada } \\
\text { com a realidade. }\end{array}$ & $\begin{array}{l}\text { Salientou que } \\
\text { a formação do } \\
\text { curso não os } \\
\text { preparava numa } \\
\text { perspectiva } \\
\text { interdisciplinar; } \\
\text { Ressaltou a } \\
\text { preocupação } \\
\text { pela falta ou por } \\
\text { não ter muito } \\
\text { conhecimento } \\
\text { sobre as meto- } \\
\text { dologias voltadas } \\
\text { para o ensino de } \\
\text { sociologia; } \\
\text { Apontou a rele- } \\
\text { vância de entrar } \\
\text { em contato } \\
\text { com trajetórias } \\
\text { de professores } \\
\text { para inspirar e } \\
\text { dar esperança } \\
\text { para continuar na } \\
\text { docência. }\end{array}$ & $\begin{array}{l}\text { Elencou pontos } \\
\text { sobre as mu- } \\
\text { danças na grade } \\
\text { curricular do } \\
\text { curso; } \\
\text { Cada escola ter } \\
\text { sua realidade; } \\
\text { Valorização } \\
\text { da força de } \\
\text { trabalho. }\end{array}$ & $\begin{array}{l}\text { Apontou a re- } \\
\text { flexão freireana } \\
\text { para pensar a } \\
\text { prática docente; } \\
\text { A importância } \\
\text { de conectar as } \\
\text { disciplinas; } \\
\text { A relevância de } \\
\text { conhecer o aluno } \\
\text { para além das } \\
\text { aparências. }\end{array}$ \\
\hline
\end{tabular}

Fonte: Elaborado pelas autoras.

Conforme suscitado, trouxemos um recorte de algumas escritas abordadas pelos estudantes durante o curso de extensão, na medida em que os encontros foram acontecendo, os estudantes foram registrando experiências formativas, colocando suas reflexões, ideias, pensamentos, sensações, alguns registraram como estavam se sentindo com a participação na formação, ressaltando a relevância de ter momentos como esses, de encontro e reflexão com docentes que estão na prática e que carregam consigo suas trajetórias pessoais e profissioanis, como um meio de oxigenar o desejo pela docência.

Destarte, conhecer as trajetórias (LAHIRE, 2005), os patrimónios individuais, nos quais, cada sujeito constrói e acumula nas suas vivências com o mundo social, conhecer algumas dessas experiências, podem fomentar significativamente os estudantes que estão em processo formativo, pois, constitui-se como uma forma possível de incentivo para docência. 
Assim, os pontos que o primeiro participante destacou, foi sobre a mudança da Grade curricular do Curso de Ciências Sociais da UFRN, que passou a compor e complementar disciplinas e atividade que dialogassem mais com a prática docente em ciências sociais e que para o mesmo seria uma forma de ampliar a formação docente e instrumentalizando-os para a prática na sua interface com o ensino de ciências sociais. Essa reflexão também foi possível observar no participante 4, que ressaltou perceber as mudanças nesse currículo, e o quanto isso é necessário para que os estudantes e futuros docentes em ciências sociais construam repertórios de conhecimentos teóricos, metodológico e prático, visto que, chamaram atenção para as dificuldades de elaboração de aulas mais dinâmicas de sociologia para os discentes do ensino médio, e que isso era um elemento central para as suas respectivas atuações.

Outra questão abordada pelo primeiro participante foi que cada escola é diferente e que por isso a teoria sociológica seria necessária e relevante para permitir a compreensão desses espaços diversificados de socialização, das relações sociais, dos conflitos e dos processos de aprendizagem e ainda registrou no diário a importância de se pensar a escola e a sala de aula, como o lugar onde se constrói conhecimentos, saberes, afetividades, sentidos e significados, visto que, a escola é um espaço de busca, de construção, de diálogos, de descobertas, de diferentes possibilidades (CANDAU, 2013) e que "não se dá em um vazio Social" (BARBOSA, 2000, p. 17), por isso, destacou a relevância de participar do curso e dos dialogos propostos, porque foram encontros de trocas e de construção coletiva.

O segundo participante evidenciou o quanto foi rica as reflexões que perpassam o conhecimento de Paulo Freire (2019) e das suas concepções de educação problematizadoras, apontando que o exercício da criticidade fomentado pelo autor, permitia o acionamento de aspectos da realidade na relação docente-discente, como por exemplo, diálogos realizados com os estudantes do ensino médio sobre a importância da escola na vida deles e suas respostas eram que a escola era uma obrigação, ou que em casa não tinham espaços tranquilos para estudar e não se sentiam motivados, entre outros desafios levantados.

Assim sendo, foi possível através das discussões freireanas, construir alternativas de aproximações desses alunos com a escola e com a disciplina de sociologia, abordando a importância de uma prática docente contextualizada com a realidade do estudante. E que essa experiência com o curso a partir dos dialogos e das reflexões sobre a prática, fizeram compreender a existência de complexificações no ambiente escolar e que esse seria um ponto que levaria consigo durante a sua relação com a docencia.

Já o terceiro participante registrou no diário formativo que o curso de ciências sociais não preparava os estudantes para uma perspectiva interdisciplinar, e ressaltou a dificuldade de se elaborar na escola projetos em parceria com outros docentes.

Destacou ainda na sua escrita a preocupação por não ter muito conhecimento sobre metodologias voltadas para o ensino de sociologia, mas também registrou a relevância de ter contato com a trajetória de docentes, que conhecer essas experiências Ihe dava mais esperança para continuar na docência. Abordou ainda, como é importante conhecer esses caminhos pelos quais outros docentes passaram, e que isso foi uma forma para pensar sobre seu processo e sobre sua caminhada na graduação e na sua experiência com o estágio supervisionado de formação.

O quarto participante, assim como, o primeiro conforme elucidado anteriormente, também destacou as mudanças na grade curricular, outro registro destacado foi que cada escola tem sua realidade e por isso 
que cursos, ciclos de debates e momentos de formação que problematizam a escola e a sua realidade são necessários. Este participante ainda ressaltou a relevância da valorização da força de trabalho docente, tendo em visto que, é um trabalho socialmente necessário e que demandam dispêndio de intelectualidade, de pesquisa, de planejamento das aulas, de buscar momentos dinâmicos e principalmente por ser uma profissão que ensina para além de conteúdos prontos e definidos por um currículo, mas que constrói as conexões e as relações dos estudantes com o mundo. Para este estudante, a sua vivência com o curso e com os dialogos foram significativos para se perceber como um agente transformador, e que essa trasnformação, perpassa pela compreensão de si na formação.

E por fim, o quinto participante também ressaltou como o segundo, a importância da reflexão freireana para se pensar a prática docente, principalmente no que tange a formação humana e social do docente, esse ponto foi central na percepção de si no processo de formação, porque segundo seu registro, entender-se como um docente que é humano, é compreender a sua incompletudo, percebendo essa lacuna que há em si, o levaria a um movimento de busca constante acerca desse sentido humano nas suas ações, e que dessa forma poderia passar a enxergar os estudantes do ensino médio com o qual convivera nas suas práticas como único, compreendendo que cada um tem sua trajetória e uma história de vida que é singular entendendo-os nas suas diversas especificidades, mas também como sujeitos históricos, sociais, culturais, subjetivos, existenciais e etc. Evidenciou-se ainda a importância de articular as disciplinas, de constituir elementos dialógicos que fomentasse uma aprendizagem mais reflexiva. 


\section{Considerações Finais}

Neste artigo, tentamos apresentar a relevância do diário formativo enquanto alternativa metodológica de formação e autoformação de estudantes, na construção de um conhecimento de si e do mundo social no qual estão inseridos.

Para refletir a respeito do diário, nos pautamos na abordagem multirreferencial que propõe analisar o objeto de pesquisa a partir de um olhar plural, permitindo o dialogo com as perspectivas diversas, para a compreensão dos sistemas educativos na sua complexidade e das relações sociais construidas socialmente e cotidianamente.

A proposta da abordagem, tem como finalidade superar o reducionismo epistêmico, que não considerem a heterogeneidade e a complexidade da realidade e da relação sujeito - objeto, tendo aproximação com as bases praxiológicas e construção da realidade, estimulando uma curiosidade mais científica sem exclusão de conhecimentos (ARDOINO, 2010)

Assim, o diário formativo foi constituído, a partir dessa perspectiva plural que tentou apreender as dimensões subjetivas dos sujeitos, mas sem deixar de lado os aspectos da realidade social. E teve como esteio, o jornal de pesquisa (BARBOSA; HESS, 2010) que propôs essa visão plural da realidade, perpassando de uma escrita pessoal para uma escrita pública, constituindo uma perspectiva dialógica e dialética de escrita particular, despreocupada, criadora, como registro livre e significativo para o sujeito que escreve, mas que traz por outro lado, a possibilidade e o desejo contido de se tornar pública, ou seja, de construir uma escrita reflexiva, crítica que permite compreender o seu processo de formação e autoformação num contexto histórico e social.

Dessa forma, foi possível apreender três perspectivas reflexivas a respeito do diário, primeiro que constitui-se como uma alternativa relevante de escrita de si, ou seja, permite que os estudantes, exercitem a escrita, o pensamento crítico e que elaborem suas próprias ideias, evidenciando o seu processo de caminhar e de aprender saberes, conhecimentos, a partir de suas próprias experiências e vivências, construindo assim, seus próprios patrimónios intelectuais individuais.

Segundo é o fomento de uma formação autônoma, crítica e reflexiva desse estudante que escreve sobre a sua formação e sobre a sua vivência com o mundo social, possibilitando a construção de diálogos e debates que renovem os processos formativos, uma vez que, ao registrar seus pontos de vista, as suas críticas, às suas considerações nos fazem compreender as prováveis lacunas na formação e com isso, delinear alternativas que sejam capazes de complementar a formação docente.

E a terceira perspectiva observada, foi que o diário formativo pode permitir ao sujeito se perceber no processo de formação, de tomar consciência das suas vivências e aprendizagens e assim transformar suas ações nas relações com os outros sujeitos e com o mundo no qual se insere de maneira integrada, ou seja, de se posicionar, de agir nos diversos espaços públicos e privados, de expressar os sentidos e significados apreendidos, de se autorizar nas relações cotidianas, de superar a mera execução das ações do dia a dia, mas construindo a capacidade de "tornar-se a si mesmo como seu próprio co-autor, de querer se situar explicitamente na origem dos seus atos e, por conseguinte, dele mesmo enquanto sujeito" (ARDOINO, 2010, p. 28) e reconhecer-se enquanto sujeito histórico, que cria, que atua na realidade e como instituinte do processo educativo e das relações sociais e não como reprodutor do instituído. 


\section{Referências}

ARDOINO, J. Abordagem multirreferencial (plural) das situações educativas e formativas. In:_ BARBOSA, J. G. (Coord.). Multirreferencialidade nas ciências e na educação. São Carlos: Editora da UFSCar, 1998. p. 24-41.

BARBOSA, J. G. Educação para a formação de autores - cidadãos. In:_ BARBOSA, J. G. (Coord.). Multirreferencialidade nas ciências e na educação. São Carlos: Editora da UFSCar, 1998. p. 7-13.

BARBOSA, J. G; HESS, Hemi. O Diário de pesquisa: O estudante universitário e seu processo formativo. Brasília: Liberlivro, 2010.

BARBOSA, Joaquim Gonçalves. Apresentação. In: __ BARBOSA, J. G; HESS, Hemi. O Diário de pesquisa: O estudante universitário e seu processo formativo. Brasília: Liberlivro, 2010. p. 15-20.

BARBOSA, Joaquim Gonçalves (Org.). Autores cidadãos: a sala de aula na perspectiva multirreferencial. São Carlos/São Bernardo: EdUFScar/EdUFSMESP, 2000.

BARDIN, Laurence. Análise de conteúdo. São Paulo: Edicões 70, 2010.

BERGER, Peter L.; LUCKMANN, Thomas. A construção social da realidade: tratado de sociologia do conhecimento. 34 ed. Petrópolis, RJ: Vozes, 2012.

BORBA, Sérgio da Costa. Aspectos do conceito de multirreferencialidade nas ciências e nos espaços de formação. In: __ BARBOSA, J. G. (Org). Reflexões em torno da abordagem multirreferencial. São Carlos: Editora da UFSCar, 1998. p. 11-19.

CANDAU, Vera Maria (org.). Reinventar a Escola. Petrópolis/RJ: Vozes, 2013.

FORMIGA, Maria das Graças Freire; BARBOSA, Joaquim Gonçalves. Jornal de Pesquisa e a quebra de resistência à escrita. In:_ BARBOSA, Joaquim Gonçalves. Cadernos de Reflexão e Debates. São Bernardo do Campo: Marília Claret Geraes Duran, abr. 2006. p. 52-65.

FREIRE, Paulo. Pedagogia da Autonomia: Saberes necessários à prática educativa. 59 ed. Rio de Janeiro/ São Paulo: Paz e Terra, 2019

HESS, Remi; WEIGAND, Gabriele. A escrita implicada. In:_ BARBOSA, Joaquim Gonçalves. Cadernos de Reflexão e Debates. São Bernardo do Campo: Marília Claret Geraes Duran, abr. 2006. p. 14-25.

LAHIRE, Bernard. Patrimónios individuais de disposições: para uma sociologia à escala individual. Sociologia, problemas e práticas, n. ${ }^{\circ} 49,2005$, p. 11-42

MELO, Elda Silva do Nascimento. Campo social e representação social da formação docente: o olhar dos agentes. Natal, RN, 2005. Dissertação (Mestrado) - Universidade Federal do Rio Grande do Norte. Centro de Ciências Sociais Aplicadas. Programa de Pós Graduação em Educação.

MINAYO, Maria Cecília de Souza. Ciência, técnica e arte: o desafio da pesquisa social. In:_ MINAYO, Maria Cecília de Souza (Org). Pesquisa Social: teoria, método e criatividade. 21 ed. Petrópolis, RJ:Vozes, 2002. p. 9-29. 
MORAIS, Erivania Melo de. Encontros reflexivos dialogais (ERD): Um recurso possível nas ciências humanas e sociais. Educação \& Linguagem. v. 22, n. 2. p. 193-206, jul.-dez. 2019.

POLLAK, Michael. Memória e Identidade social. In: Estudos Históricos, Rio de Janeiro, vol. 5, n. 10, 1992, p. 200-212. 
